\title{
Wind Energy Status and Potential Assessment across Coastal Mega City, of Pakistan
}

\author{
Sabir Ali Kalhoro, Muhammad Ali Noman, Maqsood ur Rehman Awan, Engr. Tufail Ahmed, \\ Shafique Ahmed Soomro, Muhammad Faisal
}

\begin{abstract}
The development growth of any nation is based on making a balance between power generation and its supply. But unfortunately every year Pakistan show the expansion curve between supply and demand. So the gap can be overcome by utilizing the existing renewable resources, which have the capacity to fulfill future demand. The scientific proof has been mounting for many years to use renewable energy (RE) resources. One of these shared resources is wind energy that presently seems like the primary emerging supply source of energy around the globe. The wind is such type of natural resource that capable to supply the unstoppable energy from wind turbines. The wind energy can play a significant role to supply economical and environmentally friendly energy. The wind energy only needs basic information about wind conditions for windmills installation at a localized place. So the World Bank conducts the study of each wind speed information obtained from the installed station in the selected region of the world including Pakistan for an extent of 3 years. In this research, the wind availability is being observed for the coastal megacity, of Pakistan on the basis of World Bank data.
\end{abstract}

Keywords: Wind Energy; Windmill installation; location observation; Wind Potential; World Bank Data.

\section{INTRODUCTION}

Electricity plays a vital role within the socio-economic growth and collective prosperity of any country. The energy is the basic necessity for human growth. Nowadays, low production of electricity may be a major problem in Pakistan, which directly limits the development of the state. Pakistan's population doesn't have any reliable source of electricity within the rural areas and concerning 10-12 hours load shedding in urban areas. Although the state of Pakistan continually shows a deficit within the typical resources, however, no progress was conjointly being created within the alternative resources. Therefore, it's advanced to utilize these natural assets so as to satisfy the demand-supply gap.

Pakistan is facing severe energy failure issues, with power shortage a day, accounting for financial losses. The

Revised Version Manuscript Received on August 19, 2019. University of Engineering and Technology University Karachi, Pakistan(email: sabir13es66@gmail.com)

Muhammad Ali Noman, Indus University Karachi, Pakistan(email ali.noman@indus.edu.pk)

Maqsood ur Rehman Awan, Department of Electronic Engineering, Dawood University of Engineering \& Technology, Karachi, Pakistan(email: maqsood.rehman@duet.edu.pk) University of Engineering and Technology Jamshoro, Pakistan(email: tufail.waseer@faculty.muet.edu.pk)

Shafique Ahmed Soomro, Indus University Karachi, Pakistan(email: shafiq.soomro@indus.edu.pk)

Muhammad Faisal, Indus University Karachi, Pakistan(email m.faisal.shaikh321@gmail.com)
Sabir Ali Kalhoro, Department of Electronics Engineering NED

Engr. Tufail Ahmed, Department of Electronics Engineering Mehran

electricity generation capacity is significantly inadequate than the peak demand.

The global issue due to the use of conventional resources are utmost suffering toward the crisis and therefore a substantial increase within the utilization of other alternative energy resources is globally discovered. Pakistan is among those nations that suffer an acute energy shortage [1-4].

Energy crisis and at a similar time is recognized jointly of the quickest growing marketplace for the assessment of alternative energy potential. The daily power requirement is above 20,000 MW whereas a daily shortfall of 4500-5500 MW [2] is discovered. The Pakistan coastal belts hold adequate views for the assessment of alternative energy potential and are probably at the viable locations for launching windmills. Also, some district of Punjab and a few Northern areas of West region are suitable for putting in place tiny wind farms. The Pakistan Meteorological Department (PMD), Alternate Energy Development Board (AEDB) and Government have accompanied a variety of task to assessing alternative drive in numerous regions of the country. The radical analysis for the wind speed available in the selected areas is very much significant for consistent assessments of alternative energy.

The development growth of any nation is based on making a balance between power generation and its supply. Today's generation of energy successively depends on the accessibility of renewable and non-renewable power resources. Non-renewable power sources are commonly measured in a state of depletion region especially where there is developing nations are located. Moreover, the adverse effects of fossil-fuel-based energy are leading to environmental deterioration and $\mathrm{CO} 2$ emission. Therefore, the $\mathrm{RE}$ resources not merely help in decreasing the fossil-fuel consumption however additionally reduces the possibilities of green-house impact. The renewable energy resources are slowly and gradually replacing the fossil fuel-based energy into the non-ending and eco-friendly supply of energy as a RE. This is accessible for the humanity that gives a wide supply of energy in the speedy replacement standard of existing energy sources [4-7].

With ever-increasing environmental and socio-economic awareness, government and legislative authorities, around the globe, are involved to consider the pollution-related challenges and parameters that influence the energy pattern. Therefore, renewable energy resources, like, wind, solar, and hydro are used to generate electricity to cut back

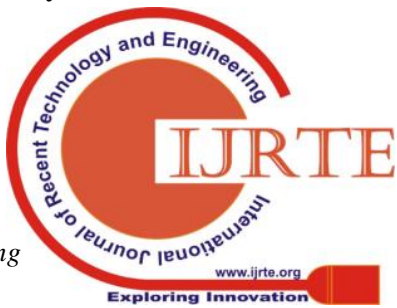


fossil-fuel-related environmental considerations. The planet desires swift, equitable, vital, and effective climate action on this stage. The scientific proof has been mounting for many years to use RE resources. One of these shared resources is wind energy that presently seems like the primary emerging supply of energy around the world. The electricity generated from the wind arrangements can be a necessary replacement for typical fossil fuel-based resources by completely diverse modalities. Though the initial cost of putting in an electrical system is comparatively high, however, the running value is incredibly low. In this, research the environmental impact and extended challenges of the technological example for the event of wind energy technology with specific relevance are discussed.

Electricity is usually a vital ingredient for the growth of a country. The deficiency touches expansion level of the country by cause's anxiety among the buyers. The energy shortage in Karachi, which is the most important town and economic hub of Pakistan is extremely impeding the progress of the town. Presently the energy deficit within the town is around $328 \mathrm{MW}$. The proposed research offers an analytical study of little residential windmills to scale back the energy shortage in Karachi. The wind potential carried to indicate the influence of the incorporation of little residential windmills in the power grid. The results show 1678MWh electricity is being saved by $50 \%$ of domestic buyer's equipped with little windmills. The paper conjointly discusses the potential resistance within the introduction of little residential windmills in the domestic sector. The potential compensations to the utility and buyers also are conferred during with the usage of the windmills [7-14].

The existing research highlight the country electricity profile state of affairs concerning with the wind energy potential. The characteristics and efficiency of the foremost wind passageway within the southern part of Sindh especially Karachi of Pakistan. Pakistan has around 1100 kilometers coastal line for the wind energy potential, however, during this research, the foremost appropriate wind corridors of the southern part of the country are being observed. The observed region conjointly tried to prove the windy area in the favorable demand of the country. Moreover, future perspective, challenges and potential are being mentioned for the energy necessity expansion contribution.

The wind is such type of natural resource that capable to supply the unstoppable energy from wind turbines. The wind energy can play a significant role to supply an economical and environmentally friendly energy. The wind energy only needs a base stand of wind conditions at the localizing under study. The wind characteristics of Jhampir and Gharo (district Thatta Sindh, Pakistan) are investigated for the traditional observation of the energy potential. The World Bank conducts the study of each 10-minutes wind speed information obtained from the installed station in the selected region of the world including Pakistan for an extent of 3 years. The hourly, monthly, seasonal, and yearly investigation is performed by suitable measured wind speed information. The different parameters are determined numerically and technically for wind energy observation.

Wind energy is a rising market in Pakistan that attract the researcher as well as a business person. While wind generation was slow to enter the country's energy market however the past six years have seen incredible growth within the wind generation sector. The three wind farms grid is interconnected to the national grid tributary over a hundred and fifty MW. Besides these comes, several other alternative projects come are at other different stages near completion. This has been due to the strengthening infrastructure, means process of proposals, foreign and personal sector's investment and engaging RE policy for the wind generation develops. If all comes mentioned reach industrial operation, wind generation can contribute a minimum of a pair $2.6 \mathrm{GW}$ electrical power and achieves its aim 5\% contribution of RE within the national energy by 2030 . The efforts for sensible expedite the expansion of the RE sector in the residential sector. The government has recently determined to require an opening from any new wind generation comes stating that within the current scenario. The wind power technologies are suitable and feasible for Pakistan, analyses research have declared. Rather than sidelining the quick-growing energy technology by the govt for the RE development in the region. The amendment of government, its methods and policies to encourage economically and price-effective investments within the sector, that is wind generation. Higher programming, energy, and risk management techniques are required to extend wind generation within the energy combine [14-19].

Wind power is that the most numerous supply of RE that is capable to equate the conventional source power generation. The wind energy is sustainable, and green source of energy offered in the selected constituency of countries.

The proposed research estimates the potential of Wind energy choices to fulfill a gap between supply and demand in the metropolis, where the policymaker aims to discuss the feasibleness of the planned comes. The target is to achieve renewable energies that supply free of energy to the metropolis in an easy way. The approach is predicated on the assets principle that a town ought to initial plan to meet its demand from its own resources so as to extend its alternative energy that supports the native economy and minimize the prices and losses related to the fuel, and transmission and distribution of electricity. The objective is to combine a pair of $2 \%$ energy need from the wind resources with the national grid. Also, the planned to syndicate the existing energy into the free supply by wind resources. The outcomes of this analysis are based on the World Bank data that involve RE potential in the belt of geographical availability of wind.

\subsection{Global to Pakistan development status of wind energy} growth

Globally, fast increasing power demand, enhance the ability prices and pursuit to attenuate the pollution of the atmosphere because of the conventional energy resources have excited to take advantage of renewable energy sources. Surrounded by different renewable energy resources the wind energy is the most leading and essential variety of power generation. Being, a pollution-free, endless and cheap sources. The wind is the quickly raising RE sources in each developing and developed countries. In Pakistan, many research is conducted within the field of RE that consists of

Published By:

Blue Eyes Intelligence Engineering 
the possible study in their exploitation. It's significantly necessary to require attentive relating to power generation from wind potential. As the speedy energy crises like oil and their prices in 1979, many policymakers, engineers, and scientists were taken interest and appraisals relating to free energy sources like wind potential. The whole put in wind energy capability of the globe since 1997-2014.

Pakistan is among the countries that face the increasing energy crisis. Pakistan fights with a variety of economic, political and social problems, the growth from existing fuels based system to the RE isn't so simple. Pakistan has been gifted with the wind source however they need steps for exploitation. The RE technology will not only penetrate the market but overcome the joblessness. The highlights of the past attract toward the development of the usual energy crisis. Up to 2009, no single RE power grid existed however currently the case has modified significantly and wind farms conducive to the national grid are a reality at this time. Many wind energy farms are inaugurated and lots of others are in pipeline. The government policy concerning wind generation systems has recently modified once surprising developments within the wind sector improvement for the wind generation combine the optimistic estimations. It is estimated that by 2030 , one-fifth of the electricity demands of the world are often met by wind energy. This is not solely environmental however economic advantages for all countries to incorporate wind generation as clean, RE supply.

Pakistan is utilizing various RE resources for energy empowerment, wind energy is one of them. The wind energy comes won't solely useful in reducing GHG emissions however conjointly decrease the billions of rupees on trading fossil fuel. The wind energy resource of Southern Sindh is rich at the Gharo and Jhampir, according to the study. The Cost-effective analysis of wind generation in the southern Sindh have already done by planner through the different categories of windmill installation.

The National Renewable energy Laboratory (NREL), USA state that Pakistan has a large quantity of wind potential nearby $346 \mathrm{GW}$. Pakistan will complete wind map and corridors in the southern Sindh by windy areas that reach $5-12 \mathrm{~m} / \mathrm{s}$ wind speed. The coastal belt of Sindh has the capacity to generate $20 \mathrm{GW}$ of electricity. Pakistan will need an enhanced ability to supply safe and secure viable power, which diminish international circumstances. It additionally offers commercially good opportunities to come back across the definite demands for energy services in the mean for rural areas as well as developing regions. Further, manufacturing employment due to native trade for the commercial aspect. The consistent international standards, essential to construct less difficult wind potential classification comprehensively, the winding passageway for wind utilization so as to suit alternative energy plant, and it's a collective compute for putting in the windmill unit in wind regions [19-26].

\subsection{Energy status in Pakistan}

According to the research, approximately 1.3 billion persons reside while not have electricity worldwide; from that, the developing ten countries have $66 \%$, one of them being Pakistan. Although the fact that the energy crisis has troubled Pakistan since its birth in 1947, this incomprehension problem confessed the development door of country. From 1947 domestic resources might meet solely two-third of electricity demand. Because the population expanded significantly, with annual growth rates quite $3 \%$ throughout the last decade, Pakistan was concerned to reduce the gap between demand and offer. The energy consumption per capita was additionally grown from $193 \mathrm{kWh}$ in 1985 to $256 \mathrm{kWh}$ in 1989, the vaster gap between offer and demand. So it was very important to balance the energy gap that absolutely growing the economy rate. Far along on, the 2000s, the energy zone received abundant consideration, the purpose is to accelerate the generation rate. In 2008, the industrial buyers were already suffering regulatory crises due to deficiency of energy run, the government declared a $75 \%$ increase within the industrial tariff from 8-10 rupees per $\mathrm{kWh}$ to 14 rupees per $\mathrm{kWh}$. Also, the rate of local use was additionally magnified from 5-7 rupees per kWh to $8-10$ rupees per $\mathrm{kWh}$. K-Electric, the most electricity supplier to the 20 million individuals of the urban center, was then suffering an amazing monetary crisis and expressed its inability to produce electricity exploitation.

The main efforts to advance Pakistan's energy sector initiated within the eighties country, while the power shortage weakened the possibilities of economic development within the country. To deal with this crisis, the government of Pakistan in 1985 enacted its first non-public power policy. This policy was geared toward non-public investors to the facility sector. The requirement for RE was accomplished by researchers and studies on resource potentials had started in the Eighties. Initially, there was an absence of complete and reliable information on wind energy resources in Pakistan. The restricted information collected by the wind instruments to see technical and economic accessibility of wind generation comes. Yet, the potential of a site for harnessing wind energy shaped.

Usually, the particular power generation is way lower because of several factors and may hit as low as $9000 \mathrm{MW}$, whereas the demand varies between 60,500 MW (summer) and 10,000 MW (winter). The country has four provinces particularly, Punjab, Khyber Pakhtunkhwa (KPK), Sindh and Balochistan. Punjab is the largest province (population-wise) with or so fifty-six of the country's total population. There's a growing demand for energy during this province. With relevance wind energy, it doesn't supply abundant potential except maybe at its Kalarkahar region that is $10-20 \mathrm{~km}$ wide and $250 \mathrm{~km}$ long. KPK is home to a twelve-tone system of the overall population of Pakistan. This province is that the smallest province by space, however, is that the most climatically diverse; with deserts, forests and tundra's all settled at intervals. Some areas of this province are known for hybrid power systems like solar-wind-hydro and there's a good potential for tiny scale turbine installations [7-23].

\section{MODEL}

Pakistan is the country in the world where there are great wind energy potentials. Electricity, in large quantities, can be produced by taking advantage of the available renewable energies. 
The wind energies of Pakistan especially Karachi have been investigated with the help of available World Bank data.

The wind energies of the selected regions give the commendable measurement which can be exploited to generate the great amount of wind energy.

The require parameter like turbulence intensity, min. wind speed, max, wind speed, mean wind speed \& wind speed standard deviation have been studied to extract the wind energy. The World Bank calculates the wind potential across Karachi on the basis of the above-given parameter. These parameters play a vital role for wind speed measurement. According to the analysis of the World Bank data, these parameters are based on wind calculation. The World Bank put this parameter on the calculation of different cities especially Karachi. The World Bank choose this parameter to calculate the wind potential of Pakistan as shown in Eq.12 to Eq.16.

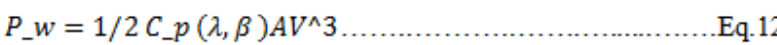

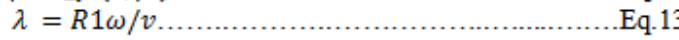

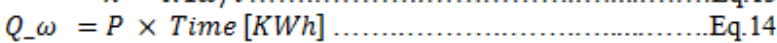

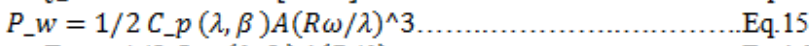

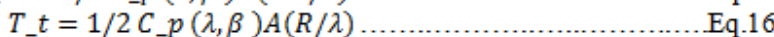

\section{EXPERIMENTATION}

The World Bank has established a wind speed based project in order to find the wind speed across different cities of Pakistan. The World Bank has set number station for the calculation of the RE power across different countries as well as Pakistan. Pakistan has got so many numbers of substations through the different cities as a part of the global effort. The Karachi is the megacity of the Pakistan and World Bank select this city for the investigation of the wind data reported in this paper.

The World Bank set the wind station for the wind potential measurement in the whole scenario. The project is installed at the "NED University of Engineering and Technology Karachi" for the RE potential measurement along with the supported team management. The data of the different parameter is acquired in a period of every ten minutes. This data is continuously getting from 2015 to 2017 for wind power observation.

\section{RESULT}

The main results as regards the require parameter like turbulence intensity, wind speed minimum (WSmin), wind speed maximum (WSmax), mean wind speed (WSmean) and standard deviation wind speed (WSsd) have been studied to extract the wind energy. The wind result shows the replica of the existing available wind into the electric power in the daily, hourly, monthly and yearly trend.

The Python software is used to indices the result to access information in a very important piece of the Pandas statistic tools. The benefits of indexed information generally still apply, and Pandas provides the time series detailed operations for the pictorial form. As a result of Pandas was developed mostly in tools for input material. The Pandas have a variety of online obtainable sources, like Google finance, Yahoo finance, and etc. Here we are going to load Google's for the Program operation.

The Pandas use to find the overall wind speed parameter like WSmin, WSmax, WSmean, and WSsd for Karachi in each kind of trendline has experimented as shown in figure.1.

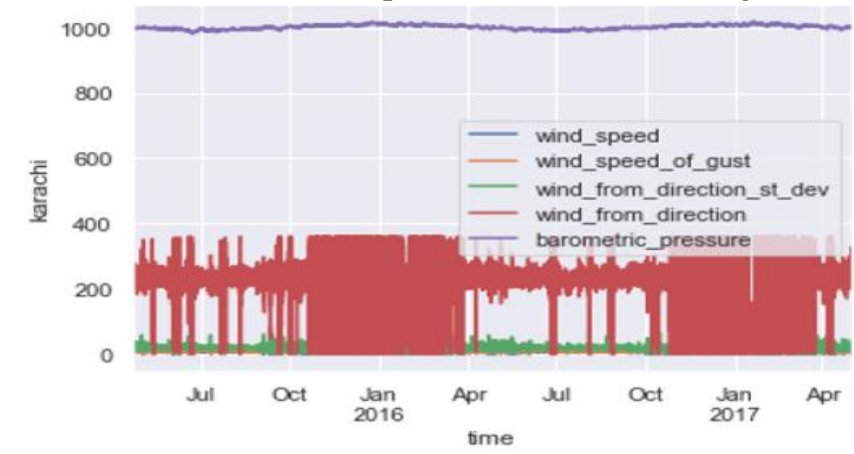

Figure.1. The wind speed parameter for Karachi for wind speed trendline is experimented.

The wind speed Parameter has experimented in a weekly count. The weekly count is best for the wind speed observed for the period of Jan 2015 to April 2017. The python gains some insight into the dataset by visualizing it. This is followed by intrigue the data. The python software will gain command by resampling the information as presented in figure. 2 .

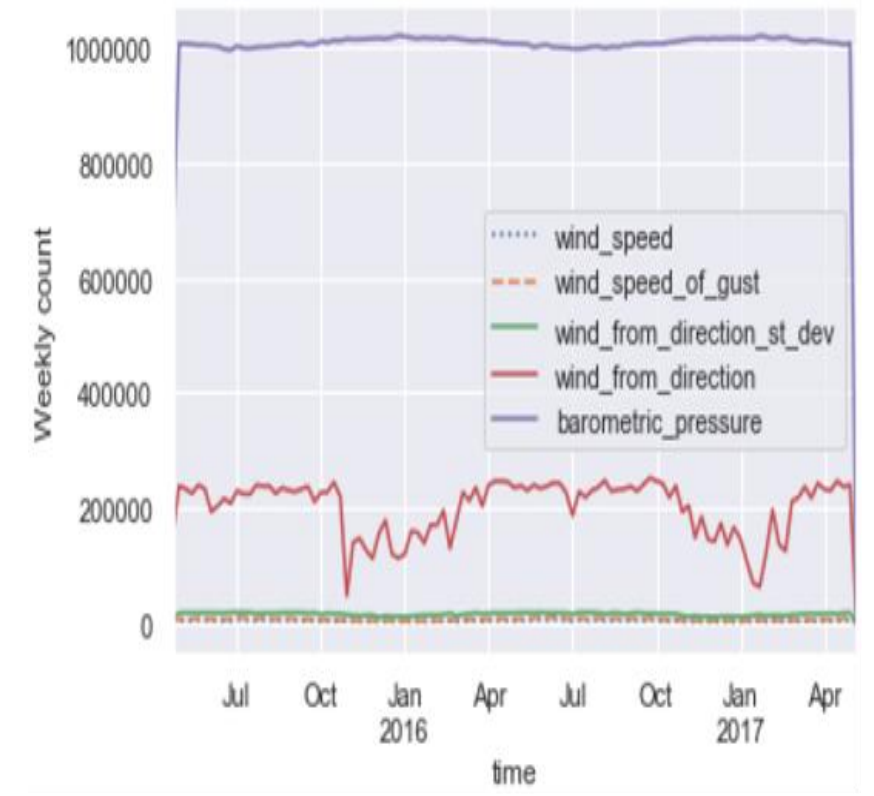

Figure.2. Wind Parameter for the Karachi are experimented in a weekly count. The weekly count for the wind speed are observed for the period of Jan 2015 to April 2017.

After the weekly count, the python is ready for the mean hourly count here the WSmin, WSmax, WSmean \& WSsd are observed as same as in the weakly count but the only difference in the parameter of wind form direction. This change in the trend as you may expect the seasonal trend of the wind speed. The perform of the speed is the difference in the summer and winter as selected season varies from week to week in a model. Wherever the python has a tendency to explore further in a very minute period of time to gives the output as publicized in figure. 3 . 


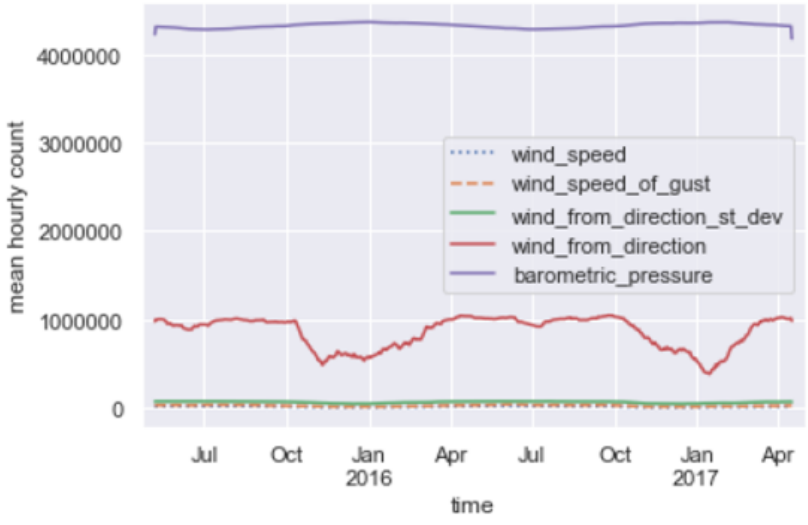

Figure.3. The wind parameter for the Karachi are experimented in a mean hourly count. The mean hourly count for the wind speed are observed for the period of Jan 2015 to April 2017.

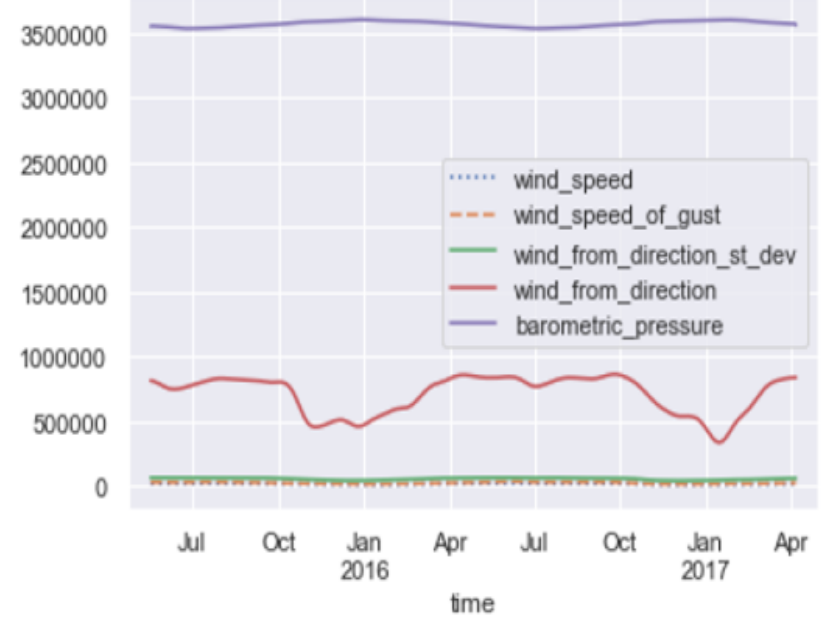

Figure.4. The periodic trend of wind parameter for the mean hourly count is experimented. The mean hourly count is investigated from Jan 2015 to April 2017.

The irregularity in the results obtained in figure. 3 and figure. 4 because the World Bank obtain data by every 10 minutes and there is almost that time period in which data is zero at a different time it shows irregularities. There are many time slot in morning and evening which give zero results so the gap shows the variances in the obtained result as shown in figure.4-5. The hourly trend of the model shows the limited variations between each hour of the observation. The wind speed generates inadequate power which depends on the weather condition within the evening and morning. In this way, the python show the hourly trend variation as refer to figure.5.

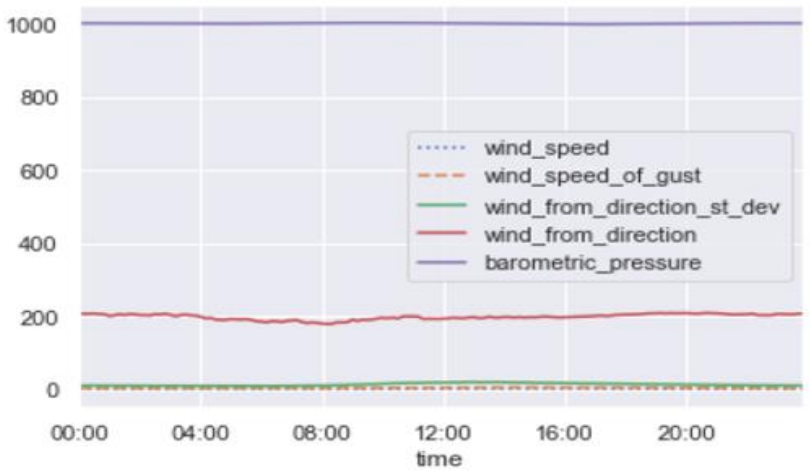

Figure.5. The hourly wind speed observation all over the day. The different parameters are calculated for the period of 27th April 2017.
While these information views measure the help to induce a plan of the overall wind speed trend in the data. The daily trend of the wind speed is gained for the whole day. The WSmin, WSmax, WSmean and WSsd show trend of the day as mentioned in figure. 6 .

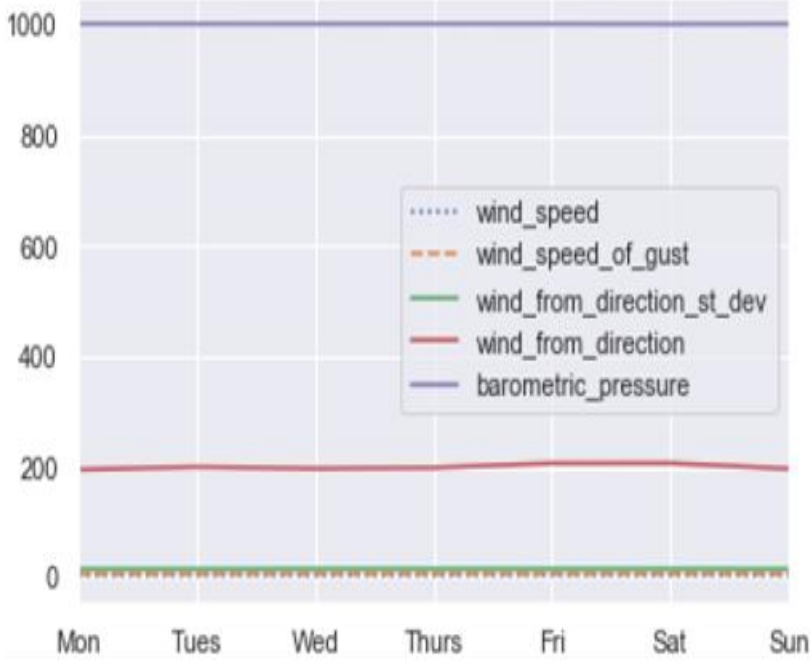

Figure.6. The daily observation of the wind speed with the reliable deviations observable throughout the day.

The weekday and the weekend trend of the wind speed are obtained to illustrate the distinction between the yield of the weekday and weekend. The wind speed for the appearance at the hourly trend on weekdays vs. weekends as presented in figure. 7 .

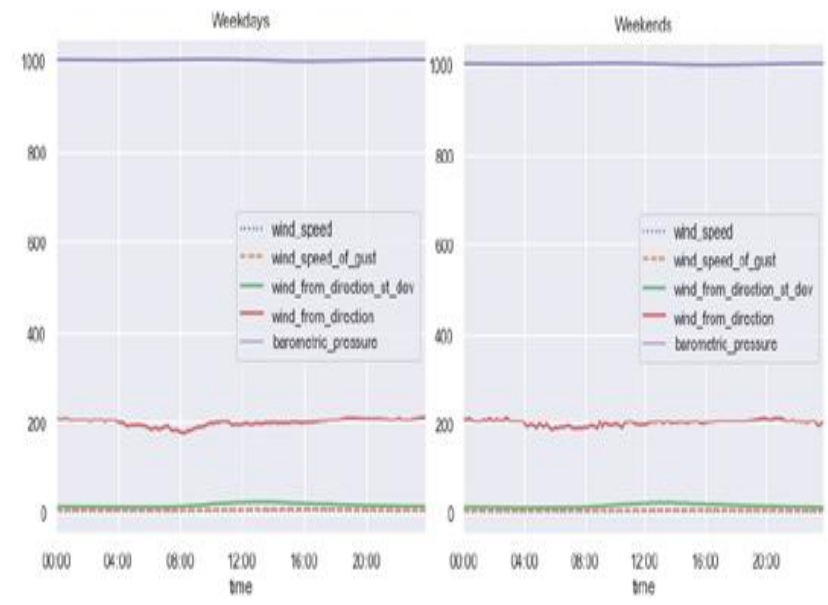

Figure.7. The wind parameter that shows hourly observation for weekday and weekend. The calculation demonstrate the hourly basis Measurement.

\section{V.RESULTS\&ANALYSIS}

The wind speed parameter like turbulence intensity, WSmin, WSmax, WSmean, and WSsd have been studied to extract wind energy. The wind result reflects the conversion of the wind into the electric power in the daily, hourly, monthly and yearly trend.

The Python software is used to guides the result to access data in a very important piece of the Pandas statistic tools.

The overall wind speed parameter is observed by Pandas

Published By:

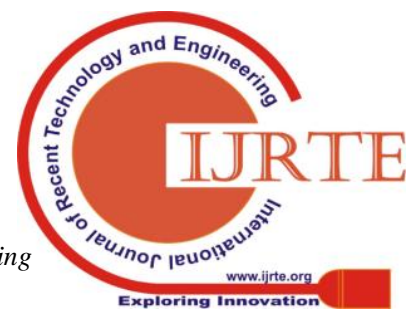


for Karachi in each kind of the wind data trendline stays experimented as exposed in figure.1.

The weekly count is best for the wind speed observed for the period of Jan 2015 to April 2017. The python takes the software command by resampling the data as offered in figure.2.

The wind speed performance will highly depend on seasonal variation from summer to winter in a model. The python explores further in a very minute period of time to gives the output as publicized in figure.3.

The World Bank obtain data by every 10 minutes so there are many time data show zero. The result show the variances in the obtained result as shown in figure.4-5. The hourly trend of the model shows the limited variations between each hour of the observation. The wind speed generates adequate power which depends on the weather condition within the evening and morning. In this way, the python shows the hourly trend variation as refer to figure.5.

The daily trend of wind speed is gained for the whole day. The WSmin, WSmax, WSmean and WSsd show trend of the day as mentioned in figure.6.

The weekday and the weekend trend of the wind speed are obtained to illustrate the distinction between the yield of the weekday and weekend. The wind speed for the appearance at the hourly trend on weekdays vs. weekends as presented in figure.7.

The obtained result terribly interesting to see wind speed modal commute pattern throughout the hourly, daily, monthly and yearly. The expanded data gives the supplementary fact, and examine the impact of the parameter that different patterns give the best trend in the hourly, daily monthly and yearly result. The observed world bank data is proving from the onshore and offshore wind resources map as shown in figure.8. The Karachi is the coastal city of Pakistan so the wind speed of this area is commendable for the electricity generation. As the wind speed is shown in the wind resource map by the World Bank group as refer figure.8.

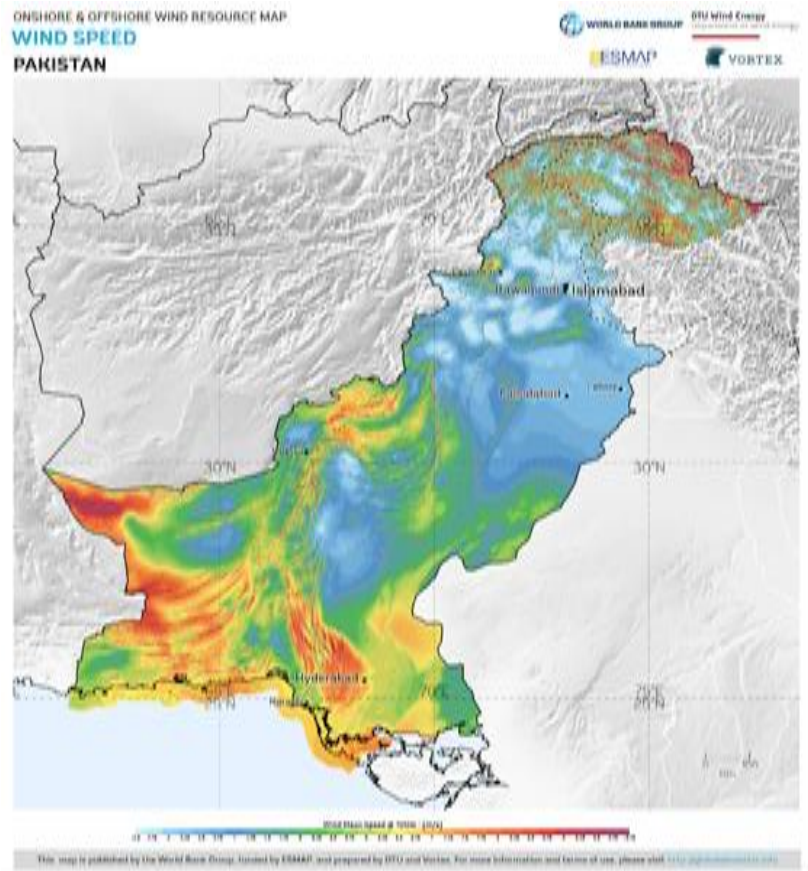

Figure.8. The Wind speed observation for the Karachi by the onshore and offshore wind resources map by World Bank. Picture Source: World Bank Group site.
The wind power density potential for the Karachi of Sindh and Balochistan are very effective as shown in figure.9. So the data available at the World Bank website for the Karachi is proving the obtainable results from figure.1-7 in the onshore and offshore wind resources map of figure.9.

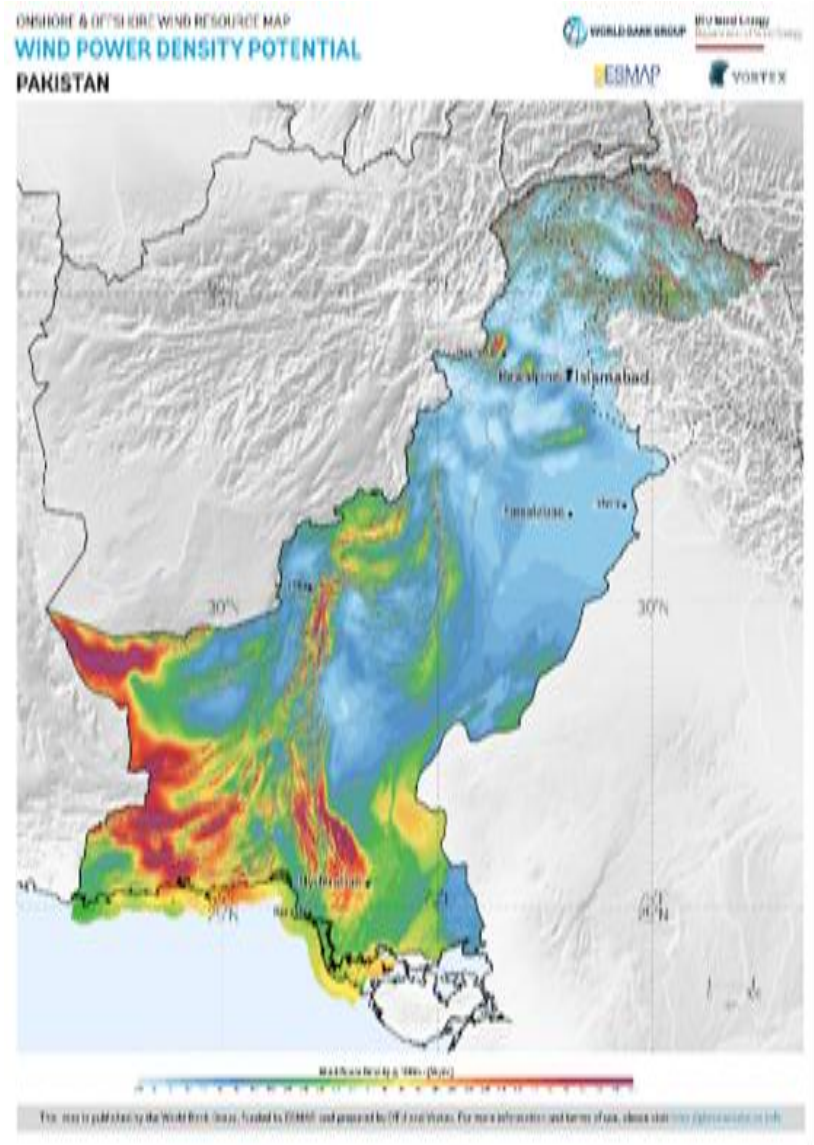

Figure.9. The Wind power density potential observation for the Karachi by the onshore and offshore wind resources map by the World Bank. Picture Source: World Bank Group site.

The wind resources map is now zoomed for the observation of the wind scenario for Karachi city. The wind map shows the wind speed at a different height, the data for the $10 \%$ windiest area is $486 \mathrm{~W} / \mathrm{m} 2$ the wind speed is increased as the height of the wind turbine increased as shown in figure. 10 . 


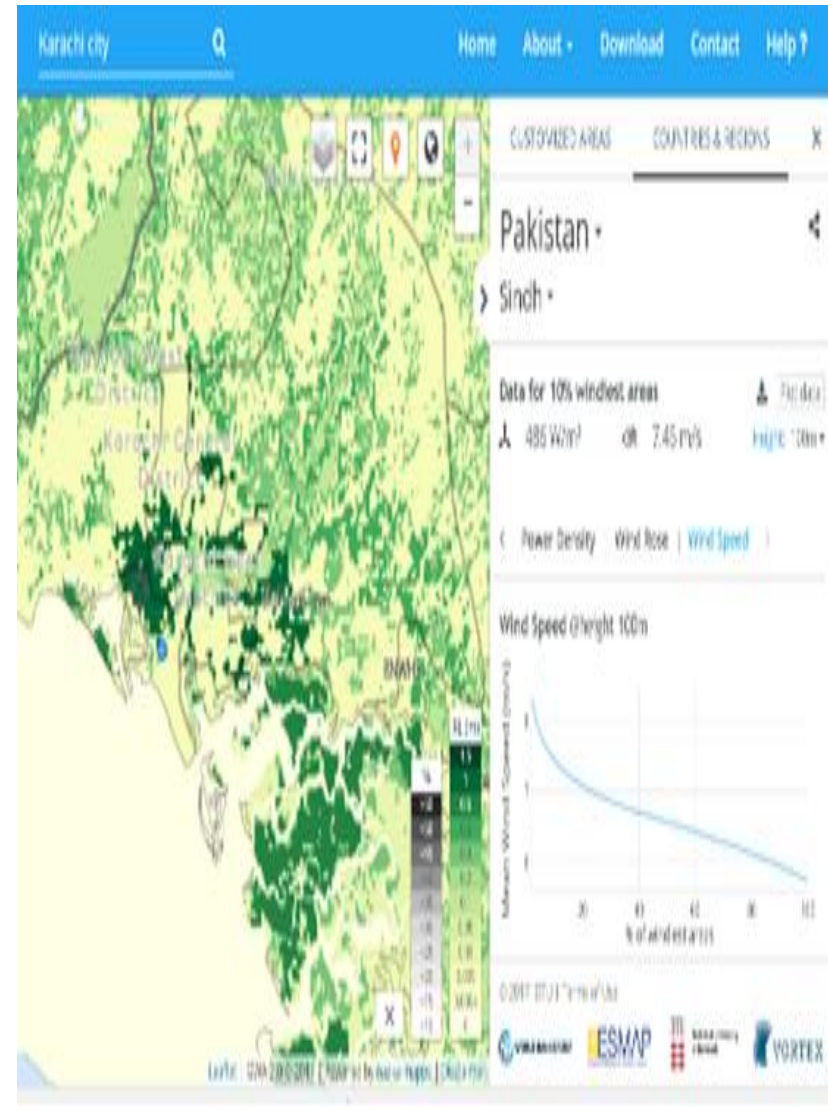

Figure.10. The Wind speed observation at the different height for the Karachi at the wind resources map. Picture Source: World Bank Group site.

The mean power density and the windiest areas were observed in this way the Karachi mean power density in the selected region is $486 \mathrm{~W} / \mathrm{m} 2$. The wind speed will be increased as the height of the wind turbine is increased as shown in figure. 11.

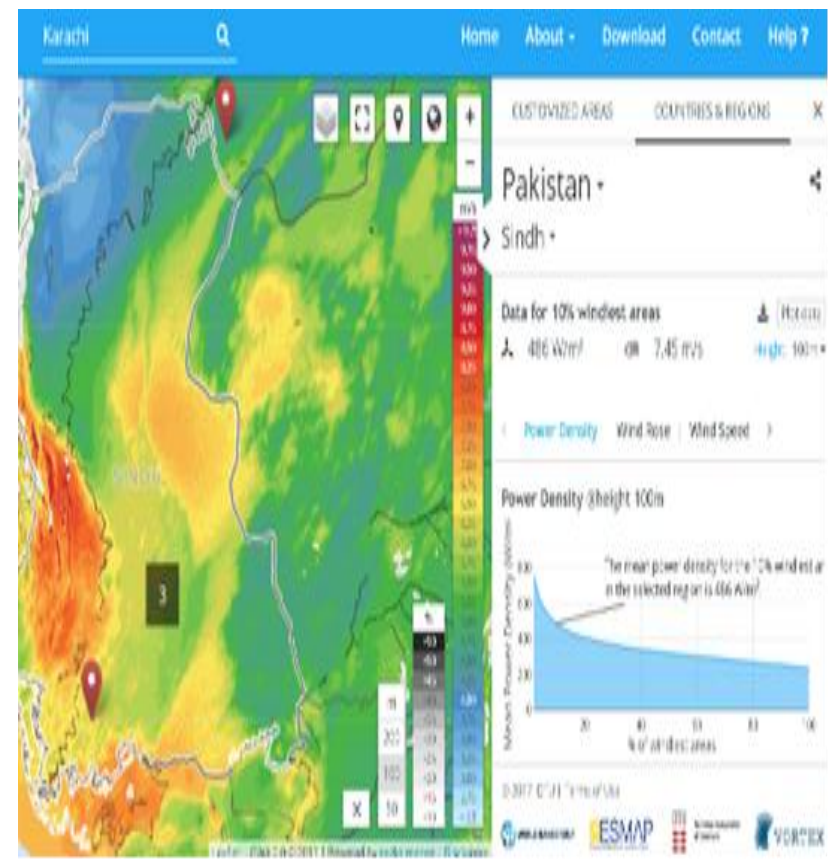

Figure.11. The observation of mean power density and the windiest areas for the Karachi at the wind resources map. Picture Source: World Bank Group site.

\section{DISCUSSION}

The World Bank group put a strong effort to explore the renewable resources in the number of countries including Pakistan. The World Bank group get the data available for all the observed countries. So the data obtained from World Bank sites located across Karachi. The wind speed data was studied for the daily, hourly, monthly and yearly periods among the data sets 2015-2017. The wind speed trend and the fluctuation as for as the windy day is concerned. We use the python software for the wind speed trend observation for the Karachi. The Pandas, a package called in Python Software is employed for handling a large set of Python world contains a range of accessible representations of dates, times, months, andimespans.

The obtained result is being experimented by the onshore-offshore wind resources map so the World Bank data for the Karachi is valid for the wind potential observation across Karachi. The obtained result will help us in windmills installation across Karachi. The planner needs to install the windmill on the basis of the World Bank data observation. In this way, the utilization of windmills, the Karachi will overcome future energy demand.

\section{CONCLUSION}

The World Bank data for renewable energy are being experimented for the wind potential observation across Karachi. The obtained result will help the planner for the installation of the windmill across Karachi. The planner needs to install the windmill on the basis of the World Bank data observation. If windmills are exploited in the selected areas, the Karachi will generate the abundant energy that overcomes the future energy demand.

\section{ACKNOWLEDGEMENTS}

Thanks World Bank for making the RE data available for Pakistan.

\section{REFERENCES}

1. S. Ahmed, A. Ali, D. Kumar, M. Z. Malik, A. H. Memon. China Pakistan Economic Corridor and Pakistan's energy security: A meta-analytic review. Energy Policy Volume 127, Pages 147-154 (April 2019).

2. K. Azad, M. Rasul, P. Halder, J. Sutariya. Assessment of Wind Energy Prospect by Weibull Distribution for Prospective Wind Sites in Australia. Energy Procedia Volume 160, Pages 348-355 (February 2019).

3. A. Ali, D. B. Rahut, M. Imtiaz. Effects of Pakistan's energy crisis on farm households. Utilities Policy. Volume 59, 100930 (August 2019).

4. Ali, S.M. Hassan; Zuberi, M. Jibran S. Tariq, M. Arsalan, B. Derek, M. Abdullah. A study to incorporate renewable energy technologies into the power portfolio of Karachi, Pakistan. Renewable and Sustainable Energy Reviews, Volume 47 (Jul 1, 2015).

5. M. M. Amana, G.B.Jasmon, A. Ghufran, A. H. A. Bakar, $\mathrm{H}$. Mokhlis. Investigating possible wind energy potential to meet the power shortage in Karachi. Renewable and Sustainable Energy Reviews 18 528-542 (2013).

6. M. H. Baloch, G. S. Kaloi, Z. A. Memon. Current scenario 
of the wind energy in Pakistan challenges and future. Perspectives: A case study. Energy Reports. 2 201-210 (2016).

7. M. K. Farooq and S. Kumar. An assessment of renewable energy potential for electricity generation in Pakistan. Renewable and Sustainable Energy Reviews 20 240-254 (2013).

8. M. S. Nazir, A. J. Mahdi, M. Bilal, H. M. Sohail, Environmental impact and pollution-related challenges of renewable wind energy paradigm - A review. Science of the Total Environment. 683 436-444 (2019).

9. S. F. Khahro, K. Tabbassum, A. M. Soomro, X. Liao, M. B. Alvi, L. Dong, M. F. Manzoor N. Ali, H. M.N. Iqbal. Techno-economical evaluation of wind energy potential and analysis of power generation from wind at Gharo, Sindh Pakistan. Renewable and Sustainable Energy Reviews 35 460-474 (2014).

10. A. Ashfaq and A. Ianakiev. Features of fully integrated renewable energy atlas for Pakistan; wind, solar and cooling. Renewable and Sustainable Energy Reviews. Volume 97, Pages 14-27 (2018).

11. M. Kamran, M. R. Fazal, M. Mudassar. Towards empowerment of the renewable energy sector in Pakistan for sustainable energy evolution: SWOT analysis. Renewable Energy. Volume 146, Pages 543-558 (2020).

12. U. K. Mirzaa, N. Ahmad, T. Majeed, K. Harijan. Wind energy development in Pakistan. Renewable and Sustainable Energy Reviews 11 2179-2190 (2007).

13. S. H. Shami, J. Ahmad, R. Zafar, M. Haris, S. Bashir. Evaluating wind energy potential in Pakistan's three provinces, with proposal for integration into national power grid. Renewable and Sustainable Energy Reviews 53 408-421 (2016).

14. M. Shoaib, I. Siddiqui, Y. M. Amir, S. Rehman. Evaluation of wind power potential in Baburband (Pakistan) using Weibull distribution function. Renewable and Sustainable Energy Reviews xxxx-xxxx (2016).

15. S. Siddique, R. Wazir. A review of the wind power developments in Pakistan. Renewable and Sustainable Energy Reviews 57 351-361 (2016).

16. I. Ullah, Q. Z. Chaudhry, A. J. Chipperfield. An evaluation of wind energy potential at Kati Bandar, Pakistan. Renewable and Sustainable Energy Reviews 14 856-861 (2010).

17. M. Shoaib, I. Siddiqui, S. Rehman, S. Khand, and L.M. Alhems. Assessment of wind energy potential using wind energy conversion system. S0959-6526 30145-3 (2019).

18. M. Shoaib, I, Siddiqui, S, Rehman, S. Khan, L. M. Alhems. Assessment of wind energy potential using wind energy conversion system. Journal of Cleaner Production. Volume 216, 10 Pages 346-360 (April 2019).

19. M. S. Nazir, A. J. Mahdi, M. Bilal, H. M. Sohail, N. Ali, H. M. N. Iqbal. Environmental impact and pollution-related challenges of renewable wind energy paradigm - A review. Science of The Total Environment. Volume 683, Pages 436-444 (15 September 2019).

20. Z. H. Hulio, W. Jiang, S. Rehman. Techno - Economic assessment of wind power potential of Hawke's Bay using Weibull parameter: A review. Energy Strategy Reviews Volume 26, 100375 (November 2019).

21. A,. Sadiqa, A. Gulagi, C. Breyer. Energy transition roadmap towards $100 \%$ renewable energy and role of storage technologies for Pakistan by 2050. Energy. Volume 147, Pages 518-533 (15 March 2018).

22. M. Shahid, S. A. Kalhoro, D. Ara, N. Bano, R. Perween. Wind and solar energy Potentials around Southern Sindh \& Southern Baluchistan provinces, especially Karachi of Pakistan. 3C Tecnología. pp. 116-141. doi: http://dx.doi.org/10.17993/3ctecno.2019. 2.116-141 (2019).

23. H. Zameer and Y. Wang. Energy production system optimization: Evidence from Pakistan. Renewable and Sustainable Energy Reviews. Volume 82, Part 1, Pages 886-893 (February 2018).

24. T. Aized, M. Shahid, A. Ali. Bhatti, M. Saleem, G. Anandarajah. Energy security and renewable energy policy analysis of Pakistan. Renewable and Sustainable Energy Reviews Volume 84, Pages 155-169 (March 2018).

25. J. McCarthy, J. Thatcher. Visualizing new political ecologies: A critical data studies analysis of the World Bank's renewable energy resource mapping initiative. Geoforum. Volume 102, Pages 242-254 (June 2019).

26. J. Urpelainen. RISE to the occasion? A critique of the World Bank's Regulatory Indicators for Sustainable Energy. Energy Research \& Social Science. Volume 39, Pages 69-73 (May 2018)

\section{AUTHORS}

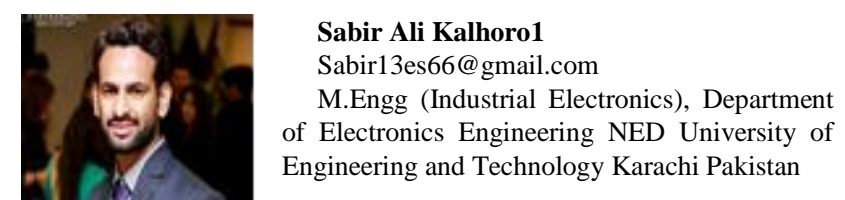

Muhammad Ali Noman2

Ali.noman@indus.edu.pk

Indus University Karachi, Pakistan

Maqsood ur Rehman Awan3

Maqsood.rehman@duet.edu.pk

Department of Electronic Engineering,

Dawood University of Engineering and Technology, Karachi, Pakistan

Engr. Tufail Ahmed4

Tufail.waseer@faculty.muet.edu

Assistant Professor, Department of Electronics Engineering

Mehran University of Engineering and Technology Jamshoro, Pakistan

\section{Shafique Ahmed Soomro5} engr_shahid82@yahoo.com Indus University Karachi, Pakistan

Muhammad Faisal6

m.faisal.shaikh321@gmail.com Indus University Karachi Pakistan 